\title{
El sistema de lo disperso. José Martí y el sujeto de la filosofía moderna
}

\section{The system of dispersion. José Martí and the subject of modern philosophy}

\section{SAMUEL Monder}

University of North Carolina, Charlotte. Estados Unidos

samonder@uncc.edu

\section{RESUMEN}

En este trabajo se examina el concepto de naturaleza en la obra en prosa de José Martí. Se trata de un concepto que ha sido largamente elaborado por la filosofía moderna antes de su apropiación literaria por parte del romanticismo. Así, comienzo reseñando algunas ideas filosóficas típicas de la modernidad que considero relevantes para entender los argumentos que siguen. Si mi interpretación es correcta, Martí maneja un doble concepto de naturaleza: por una parte, se trata de una fuerza que actúa de acuerdo con leyes poéticas precisas (leyes que habrán de ser descubiertas por poetas); por otra parte, es un poder disruptivo que sistemáticamente destruye cualquier sistema que construyamos para encapsular sus productos. Finalmente, señalo algunas maneras en que la discusión precedente puede usarse para dar cuenta de algunas conexiones entre los proyectos poéticos y políticos de Martí.

Palabras claves: Filosofía, modernidad, naturaleza, sujeto cartesiano.

\section{ABSTRACT}

This paper is devoted to an examination of the concept of nature in José Marti's prose work. The concept of nature has been highly elaborated by early modern philosophers well before its appropriation by romantic writers. Thus, I start by charting some typically modern philosophical ideas, which I deem relevant to the following discussion. I think Marti's account of nature is double layered: on the one hand, it is a force that acts according to precise poetic laws (laws that are to be found by poetic minds); on the other hand, it is 
a disrupting power that systematically tears apart any system that we build to encapsulate its very own workings. Finally, I point out some ways in which the preceding discussion can be used to explain some connections between the political and the aesthetic projects of Martí.

Keywords: Philosophy, modernity, nature, cartesian subject.

Recibido: 23-02-2009. Aceptado: 03-05-2009.

1.

e acuerdo con una importante tradición crítica, el surgimiento de la novela europea debe entenderse a la luz de ciertos desarrollos en la filosofía moderna. Pensemos, por ejemplo, en los trabajos de Ortega y Gasset (Meditaciones del Quijote), Lukács (Die theorie des romans), Watt (The rise of the novel) o Kundera (L'Art du roman). No es que todos estos autores sostengan el mismo punto de vista; no hay una única manera de poner en relación los múltiples problemas de la filosofía moderna con un evento particular en la historia literaria. Sin embargo, sólo para dar un ejemplo, quizás valga la pena mostrar, aunque de modo esquemático, una estrategia que puede usarse para establecer las conexiones relevantes: se comienza por señalar que el sujeto cartesiano, siendo pura interioridad, supone un afuera; luego, se saca una consecuencia menos inocente: lo que queda afuera es toda clase de objetos pesados o livianos, en estado sólido, líquido o gaseoso (el mundo exterior, le dicen los filósofos), respecto de los cuales el sujeto mantiene una relación meramente representativa. La construcción de una conciencia tan aislada, tan encerrada en sí misma, tan absolutamente separada del mundo y de sus robustas certezas, demanda un nuevo tipo de narrativa que pueda dar cuenta de la infinita fractura epistémica que se abre ante nosotros. ¿Sueño o estoy despierto (se pregunta el sujeto moderno)? ¿Existe algo ahí afuera? ¿Cómo saberlo? ¿Cuál es el criterio? La novela europea sería, entonces, hija feliz del divorcio entre el sujeto y el mundo exterior.

Ahora bien, ¿cuán lejos de Europa puede llevarse una estrategia crítica similar? ¿Cómo construir un aparato crítico que nos permita contemplar diferentes constelaciones estéticas sobre el horizonte de los problemas de la filosofía moderna? No se trata, simplemente, de importar un paradigma crítico para probar su eficacia en el campo de las letras hispanoamericanas; más bien, creo que un enfoque de esta naturaleza nos proporciona una clave importante para relacionar discursos de legitimación y proyectos estéticos, algo particularmente 
relevante dentro de una literatura en la que abundan textos de corte fundacional, tales como Facundo, Martín Fierro o "Nuestra América", sólo para citar unos pocos ejemplos. Debemos observar que estos grandes relatos se caracterizan por la construcción de sujetos, más que por la creación de personajes folklóricos, míticos o fantásticos sobre los que se deposita un saber de orden superior. En el mundo dentro del cual se legitiman estas narrativas, de nada sirve apelar a dioses o a tradiciones ancestrales para fundar un saber, una identidad o una nación. La modernidad consiste, entre otras cosas, en negar que las leyes universales sobre las que está fundada la actividad humana -en sus aspectos epistémicos, morales o políticos- se encuentren inscriptas en una voluntad divina que un sacerdote puede descifrar o un soberano personificar. Legitimar estas leyes involucra ahora, más que recibir un mandato de "afuera", reflexionar sobre los alcances y límites de nuestras propias facultades. Para entender el mundo exterior hay que mirar hacia adentro. Esta revolución en la historia del pensamiento suele asociarse a la emergencia del sujeto moderno, aclamado héroe de ciertas narrativas filosóficas en torno a la búsqueda de la verdad.

2.

En el "Prólogo al poema del Niágara” (VII 123-238), José Martí utiliza una estrategia argumentativa en la que se reconoce la marca de algunas de las grandes obras de la filosofía moderna. Se trata del uso de una estructura de tres pasos: se comienza por (a) la descripción de un mundo de opiniones caprichosas, cambiantes y contradictorias en el que nos extraviamos una y otra vez en la búsqueda de la verdad; situación ésta ante la que se propone (b) el repliegue del sujeto sobre sí mismo, buscando respuestas en su interior, analizando sus ideas, evaluando sus capacidades; a lo que sigue (c) el encuentro de un nuevo fundamento en el seno de nuestra interioridad.

Para familiarizarnos con esta estructura tripartita propongo que, para comenzar, consideremos, auque sea muy brevemente, algunos textos filosóficos. Veamos un ejemplo tomado del Discurso del método. Primer paso:

... siendo estudiante descubrí que no era posible concebir nada lo suficientemente extraño o increíble como para no haber sido propuesto por algún filósofo; y desde entonces, a través de mis viajes, he comprobado que quienes sostienen puntos de vista totalmente contrarios a los nuestros no son de ninguna manera bárbaros o salvajes, sino que muchos de ellos usan de la razón tanto o más que nosotros (AT VI 16). 
Segundo paso:

Es así que me sentí incapaz de encontrar a alguien cuyas opiniones me parecieran preferibles a las de cualquier otro, no teniendo entonces más remedio que convertirme en mi propia guía (AT VI 16).

En el sistema de Descartes, esto significa el examen de todas las ideas a partir del riguroso ejercicio de la duda metódica, lo que -luego de la devastación que produce la hipótesis del genio maligno- conduce al tercer paso, es decir: el momento del cogito, el descubrimiento de un criterio de verdad basado en la claridad y la distinción de las ideas, y las pruebas de la existencia de Dios.

Otro texto muy conocido que podemos citar como ejemplo es la "Epístola al lector”, que sirve de prólogo al Ensayo sobre el entendimiento humano, de John Locke:

Si no fuese inconveniente contar la historia de este ensayo, debería decir que cinco o seis de mis amigos, encontrándose en mi habitación, discutían una cuestión muy alejada de ésta, cuando de inmediato se vieron asediados por dificultades que aparecían a cada lado. Después de un rato de intentar componer ese rompecabezas sin aproximarnos siquiera a la solución de las dudas que nos tenían perplejos, se me ocurrió que habíamos tomado el camino equivocado; y que antes de lanzarnos a investigaciones de esa naturaleza, era necesario examinar nuestras propias habilidades y ver qué objetos eran aptos para nuestro entendimiento, y cuáles no (E 7).

Aquí tenemos los dos primeros pasos en versión minimalista. Observemos que se sigue rigurosamente el mismo modelo: la perplejlidad y el consecuente repliegue sobre la interioridad del sujeto para examinar sus capacidades; de esto resultará algo muy diferente de lo postulado por Descartes, por cierto. En este caso, el examen de las ideas no arroja rastro alguno de presencia divina; y el fundamento de nuestro conocimiento, más bien, lo proporcionan las ideas simples que se originan en nuestros sentidos.

Veamos ahora un último ejemplo tomado de la introducción al Tratado de la naturaleza humana, de Hume:

$\mathrm{Ni}$ siquiera se necesita un profundo conocimiento para descubrir la situación imperfecta de las ciencias de nuestro tiempo; aun el más ignorante puede juzgar que no todo va bien puertas adentro a partir del ruido y griterío que escucha desde afuera. No hay nada que no sea objeto de debate y en lo que los entendidos no tengan opiniones contrarias. 
Ni siquiera se salvan de la controversia las cuestiones más triviales y, en las más urgentes, no somos capaces de tomar decision alguna. Las disputas se multiplican como si todo fuese incierto; y se desarrollan con la mayor vehemencia, como si todo fuese cierto. En medio de todo este alboroto no es la razón la que se lleva el premio, sino la elocuencia; y ningún hombre necesita desesperar por ganar prosélitos para la hipótesis más extravagante si posee suficiente arte como para presentarla con colores favorables. La victoria no la ganan los hombres de armas, los que manejan la pica y la espada, sino los cornetas, tamboriles y músicos del ejército ( $\mathrm{T}$ xiv).

A esta altura, ya podemos reconocer una escena familiar: controversias interminables, la sensación de que todo está en cuestión, de que todo es ruido y griterío. El segundo paso que da Hume tiene que ver con su proyecto de estudio de la naturaleza humana, lo que debe entenderse como el repliegue del sujeto sobre sí mismo para considerar los fundamentos de la experiencia, a saber: las percepciones de la mente; el tercer paso es el descubrimiento de las leyes mediante las cuales la imaginación forma distintas series de percepciones.

Ahora bien, como habíamos ya adelantado, en el "Prólogo al poema del Niágara" Martí se ajusta a este esquema de un modo paradigmático para referirse al lugar que ocupa la poesía en un mundo vertiginoso y fragmentado:

No hay obra permanente, porque las obras en los tiempos de reenquiciamiento y remolde son por esencia mudables e inquietas; no hay caminos constantes, vislumbrándose apenas los altares nuevos, grandes y abiertos como bosques. De todas partes solicitan la mente ideas diversas -y las ideas son como los pólipos, y como la luz de las estrellas, y como las olas de la mar (VII 225).

Ante esta situación, Martí propone algo que parece seguir fielmente la receta de la filosofía moderna: en un gesto típicamente cartesiano, el poeta se sumerge en su propia subjetividad, encontrando un espacio privilegiado en el que reina la certeza de su propia existencia:

Ni líricos ni épicos pueden ser hoy con naturalidad y sosiego los poetas; ni cabe más lírica que la que saca cada uno de sí propio, como si fuera su propio ser el asunto único de cuya existencia no tuviera dudas... (VII 225).

He aquí, entonces, el espacio en el que habrán de sentarse los fundamentos de la nueva poesía: 
(...) la vida íntima febril, no bien enquiciada, pujante, clamorosa, ha venido a ser el asunto principal y, con la naturaleza, el único asunto legítimo de la poesía moderna (VII 229).

Pero, de inmediato, Martí va a mostrar que, en verdad, la vida íntima está hecha de cárceles y convenciones. La verdad está en otra parte.

¡Más, cuánto trabajo cuesta hallarse a sí mismo! El hombre apenas entra en el goce de la razón, que desde su cuna le oscurecen, tiene que deshacerse para entrar verdaderamente en sí. Es un braceo hercúleo contra los obstáculos que le alza al paso su propia naturaleza y los que amontonan las ideas convencionales de que es, en hora menguada, y por impío consejo, y arrogancia culpable, alimentada. No hay más difícil faena que ésta de distinguir en nuestra existencia la vida pegadiza y postadquirida, de la espontánea y prenatural; lo que viene con el hombre, de lo que le añaden con sus lecciones, legados y ordenanzas, los que antes de él han venido. So pretexto de completar el ser humano, lo interrumpen. No bien nace, ya están en pie, junto a su cuna, con grandes y fuertes vendas preparadas en las manos, las filosofías, las religiones, las pasiones de los padres, los sistemas políticos. Y lo atan; y lo enfajan; y el hombre es ya, por toda su vida en la tierra, un caballo embridado. Así es la tierra ahora una vasta morada de enmascarados. Se viene a la vida como cera, y el azar nos vacía en moldes prehechos. Las convenciones creadas deforman la existencia verdadera, y la verdadera vida viene a ser como corriente silenciosa que se desliza invisible bajo la vida aparente, no sentida a veces por el mismo en quien hace su obra cauta, a la manera en que el Guadiana misterioso corre luengo camino calladamente por bajo de las tierras andaluzas (VII 229-230).

Siendo esto así, podemos advertir que hallarse a sí mismo es una tarea mucho más compleja de lo que han soñado los filósofos. Cuando pensamos en nuestra "interioridad", en verdad, sólo estamos pensándonos en términos de una serie de moldes y convenciones cuyas marcas de fábrica pueden reconocerse de lejos. De hecho, podríamos argumentar que el concepto mismo de interioridad es sólo un molde algo artificial. En efecto, haríamos bien en preguntar: ¿De qué interioridad hablan los filósofos? ¿Interioridad? ¿Respecto de qué cosa? ¿Qué es esa metáfora espacial en torno a la cual construyen la noción de sujeto? De paso, notemos el lugar que, en el párrafo citado más arriba, ocupan los filósofos: parados al lado de nuestras cunas, junto a padres y sacerdotes, listos para encerrarnos en sus jaulas conceptuales. 
Ahora bien, ¿qué es lo que descubrimos una vez que hacemos abstracción de todos estos sistemas que, al decir de Martí, nos atan, nos enfajan y nos embridan? La naturaleza aparece como uno de los obstáculos con los que debemos luchar; en cambio, aquello que, al decir de Martí, se desliza invisible como un río subterráneo bajo la vida aparente, recibe el nombre de vida prenatural. Este es un concepto sumamente importante. Y sin embargo, resulta paradójico que se mencione una sola vez para luego desaparecer por completo (justamente como el río subterráneo, que es su símbolo). ¿Por qué distinguir entre naturaleza y prenaturaleza? El punto más importante aquí es que, de inmediato, Martí se "olvida" del concepto de prenaturaleza para continuar hablando, simplemente, de naturaleza. Creo que esta momentánea indecisión que ofrece el texto, titubeando entre dos términos diferentes, ayuda a plantear una sospecha: que bajo las convenciones que definen la intimidad hay algo que puede ser entendido de modos muy diferentes aunque no excluyentes entre sí.

Ya volveremos sobre ese punto. Mientras tanto, sin ánimo de embarcarme en una discusión demasiado ambiciosa, quisiera sugerir que hay dos tradiciones respecto de las cuales podemos ubicar el trabajo conceptual de Martí. La primera suele identificarse con el pensamiento de Rousseau: la naturaleza como metáfora de una unidad originaria. Desde este punto de vista, se postula un estado previo a las contradicciones que trae la vida civilizada. Podemos advertir aquí uno de los lugares comunes de la tradición romántica; y no es ésta la lectura que voy a proponer. Creo que para entender la postura de Martí, debemos atender a una segunda línea de pensamiento: una en la que la naturaleza es concebida como fuerza. Me parece que el filósofo que desarrolla con mayor detalle esta noción es David Hume. En su obra, la naturaleza es una fuerza que trabaja manteniendo la cohesión de partes enteramente diferentes, permitiendo, por ejemplo, que los planetas giren en órbitas regulares sin chocar entre sí ni destruirse. Esta maravilla cósmica se debe a que las cosas operan de acuerdo con determinadas leyes. Hume sostiene que la naturaleza no sólo mantiene su regularidad respecto de las órbitas de los planetas, sino que tambien sus mismas leyes se hacen patentes en los giros y vueltas de nuestras ideas y pasiones; de ese modo, Hume espera sentar las bases de la ciencia que proporcionará los fundamentos de nuestros sistemas epistémicos, morales y políticos ${ }^{1}$. Ahora bien, quisera sugerir que Martí comparte esta línea de pensamiento. En este sentido, podríamos decir que para Martí la naturaleza opera a partir de una ley fundamental: la ley de analogía; una ley que no descubren los físicos, ni los

${ }^{1}$ Hume desarrolla estas ideas en diferentes partes. Véase, por ejemplo, la Introducción y el Libro I Parte 1 del Treatise. 
psicólogos, sino los poetas. Aquí encontramos la base común que comparten sus teorías estéticas y políticas.

Para seguir el desarrollo de esta cuestión, debemos leer el ensayo sobre Whitman (XIII 131-143). En este lugar, la naturaleza es una fuerza que otorga unidad a lo diverso. La naturaleza no impone homogeneidad a partes desiguales, no aplasta la individualidad a favor del género o de la especie; no posee las cualidades formales de un sistema, sino la vida de un organismo. La naturaleza, en tanto fundamento, no garantiza la verdad de nada, no legitima nada, no valida ninguna creencia, no sirve para condenar a nadie, ni para excomulgar a nadie, no reconoce iniciados, pero tampoco herejes. Lo único que hace la naturaleza es garantizar una sola cosa: la ausencia de contradicciones. La naturaleza es un sistema de diferencias sin contradicción. Si podemos ver que un individuo es un microcosmos, estamos cerca de la verdad. Si podemos ver que en el más pequeño ser brilla el universo entero, hemos comenzado a entender (XIII 136).

Martí invierte aquí uno de los problemas típicos de la filosofía moderna: porque su preocupación no es la dispersión o el fragmento, sino más bien la unidad que se impone sobre lo disperso: la violencia del sistema que pretende unidad en la gloriosa diversidad de la Tierra. La cuestión no es ver la unidad del todo; por el contrario, se trata de ver el todo en el individuo. Esta es, sin duda, una visión poética; no es el científico el encargado de validarla; sin embargo, se establece a partir del descubrimiento de una ley fundamental, que aparece formulada de modo muy claro en el ensayo sobre Emerson (XIII 17-30). Según lo que leemos en este texto, la ley que descubre el poeta es la ley de analogía, que garantiza la no contradicción de lo diferente:

El [Emerson] no ve más que analogías: él no halla contradicciones en la naturaleza... (XIII 23).

Las contradicciones no están en la naturaleza, sino en que los hombres no saben descubrir sus analogías (XIII 29).

¿De qué manera la analogía destruye la contradicción? Sólo un ejemplo. Pensemos en las confrontaciones armadas, en cómo los noticieros se esfuerzan en ocultar imágenes de sufrimiento, en cómo sólo ofrecen -junto con consignas triunfalistas- una vista aérea de la guerra, algo que la asemeja a un video game. Desde luego, la idea es no mostrar nada que podamos reconocer como el dolor de un semejante. Porque mostrar al otro como a un semejante implicaría vernos a nosotros mismos en el otro, operación mediante la que se destruye la rudimentaria retórica basada en un sistema de oposiciones (ellos/nosotros, 
bien/mal, civilización/barbarie, etc.) sobre la que suele girar todo discurso de justificación de la guerra.

La naturaleza, entonces, se define de modo puramente negativo como garantía de no contradicción: garantiza simplemente que no existe conflicto alguno fuera de las contradicciones internas de un sistema de representación dado. En otras palabras, las contradicciones deben ser atribuidas al sistema: nunca a aquello que el sistema fracasa (sistemáticamente) en capturar. Sin embargo, aquí mismo nos encontramos con una nueva determinación del concepto de naturaleza; porque en este preciso punto refiere a aquello que excede todo sistema, al resto que resiste toda sistematización.

Deseo sugerir que esta última idea es la que irrumpe en el análisis del sujeto que nos proporciona Martí en el "Prólogo al poema del Niágara". Y esto explica, en tal contexto, la referencia a lo prenatural. La naturaleza no sólo es el mero excedente que se revela cuando nos libramos de toda convención, de todo sistema y de toda "cárcel" conceptual; es lo que continuamente está más allá de toda organización conceptual: más allá aun de la categoría misma de naturaleza; es lo que, una vez ordenado todo, permanece desordenado. Es lo que nunca se alínea con el eje de la visión, como dice Martí en el ensayo sobre Emerson (XIII 29); es la regular irregularidad de las cadenas montañosas, como dice en el ensayo sobre Whitman (XIII 132).

Vemos de qué manera, entonces, Martí se apropia del sujeto de la filosofía moderna, trabajando sobre lo que podríamos denominar su reverso: en primer lugar, el sujeto martiniano no funda ningún conocimiento, sino sólo una poética; en segundo lugar, mientras el sujeto cartesiano enfatiza el punto mismo en que ser y pensar se identifican, para Martí, en tal lugar, más bien, se verifica una diferencia fundamental. Esta última tesis requiere una breve explicación. Si mi interpretación es correcta, hay dos maneras de pensar el sujeto: como constituido por sus ideas o por sus facultades. Si los datos básicos del conocimiento son las ideas, la tarea de fundamentación del conocimiento consiste en identificar aquellas representaciones que poseen un privilegio epistémico: éste es el caso, por ejemplo, de las ideas claras y distintas para Descartes, de las ideas simples para Locke o de las impresiones para Hume. Al menos ésta es la versión "oficial" del sujeto moderno, aquella que recoge casi cualquier manual de filosofía. Sin embargo, el sujeto también se encuentra constituido por facultades, por ejemplo: los sentidos, la imaginación y la razón. Desde esta perspectiva, las cosas se ven de un modo distinto: el sujeto se encuentra atravesado por diferentes tensiones que se producen entre las facultades como resultado de la inconmensurabilidad de las mismas. Dentro del sistema cartesiano, un ejemplo es nuestra idea de infinito, que puede 
ser concebida claramente por la razón, siendo irrepresentable, sin embargo, para la imaginación. Notemos también que la teoría del error que propone Descartes se basa en un exceso de la voluntad, que es ilimitada, respecto de la imaginación, que es limitada. Otro ejemplo, central para el cartesianismo, tiene que ver con la idea de la unión del alma y el cuerpo. Según confiesa Descartes a la princesa Elisabeth, ésta es una idea que la razón no puede conocer sino muy oscuramente, pero que en cambio es conocida muy claramente por los sentidos (Carta de Junio 28, 1643). Fuera del ámbito del cartesianismo, observemos que el tema más importante de la filosofía de Hume quizás sea el conflicto entre entendimiento e imaginación, que termina siendo un conflicto interno de la imaginación, de ésta consigo misma, entre sus usos regulares e irregulares. Los ejemplos podrían multiplicarse, pero quizás estos pocos basten para señalar que, desde esta perspectiva, el sujeto no se encuentra definido en términos de una representación privilegiada, sino más bien en función de un error sistemático, en tanto las facultades exceden constantemente sus propias capacidades de representación. Quisiera sugerir que este último es el sujeto problemático de la modernidad: perisférico en los sistemas filosóficos, que tratan de eliminar o minimizar sus efectos, pero central para el trabajo de Martí. Contrariamente al ideal del cogito, en este caso, pensamiento y existencia no coinciden, ya que hay algo que permanentemente queda fuera de nuestros sistemas de representación. Este es, para Martí, el objeto de la poesía, pero también, desearía argumentar, el de la teoría política. ¿Cómo entender la organización del Estado en términos de un exceso que de ningún modo debe ser identificado como barbarie, sino como mero fracaso de nuestros sistemas políticos, como un desorden creado por un determinado sistema de producción? (VI 17) ¿Y qué pasaría si un gobernante trabajase este desorden a la manera de un poeta? En la última sección de este trabajo sugeriré una lectura de "Nuestra América" (VI 15-23) subrayando las relaciones entre estética y política en el pensamiento de Martí.

\section{3.}

Hablar de "nuestra" América supone una primera persona plural; en otras palabras: se trata de suponer unidad en una pluralidad. Ahora bien, podemos sospechar que la unidad que implica ese "nosotros" no se corresponde con una disposición de la geografía, ni mucho menos con un decreto divino. Por cierto, la unidad que tiene en mente Martí no es territorial; de hecho, postular una América que es "nuestra" nos lleva de inmediato a pensar en otra América que es la de los "otros". Y una rápida mirada a nuestro alrededor nos lleva también a la convicción de que que no existe unidad racial, cultural o ideológica. 
Una vez establecido este punto, deberemos considerar que el problema de la identidad latinoamericana es una cuestión política, no una temática metafísica: en nada ayuda plantear teorías que apelen al ser o a la esencia del hombre americano. De este modo, no debe extrañarnos que estas reflexiones de Martí se encuentren vinculadas a una meditación sobre el arte de gobernar, lo que es entendido en términos de la capacidad para ver unidad en un cuerpo social heterogéneo.

Este arte debe hacer surgir, de factores descompuestos, naciones compactas. La clave de la unidad americana consiste, verdaderamente, en su falta de identidad: nuestra América es el reino de las asociaciones imposibles; un cuerpo con "los pies en el rosario, la cabeza blanca y el cuerpo pinto de indio y criollo" (VI 16). En este sentido, debemos considerar el rol que Martí adjudica al conocimiento: su uso es analítico, no sintético; aunque resulta necesario a la hora de establecer una topografía de la diferencia, la síntesis es siempre operada por facultades no epistémicas. Desde luego, la unidad no es facultad del conocimiento, sino un acto en el que la voluntad política se une a la imaginación poética: "Gobernante en un pueblo nuevo significa creador" (VI 14).

En lo que respecta al conocimiento, la tarea que nos compete es fundamentalmente negativa: debemos quitarnos las gafas conceptuales que impiden la visión de la diferencia (las "antiparras yanquis y francesas"). Ningún libro extranjero da respuesta al enigma americano, afirma Martí (VI 33). Porque, en tal caso, terminamos ocultando la realidad tras un esquema artificial (ocultándola, marginándola o asesinándola). En particular, debemos evitar el modelo de la exclusión. Las antiparras importadas impiden ver la diferencia. Por eso, según Martí, aunque las levitas son aún de Francia, el pensamiento comienza a ser americano (VI 18).

"Pensar es servir" (VI 20). En este sentido, el pensamiento, que es ciego para los valores, es un instrumento al servicio de los mismos: porque éstos no se derivan del conocimiento, ni necesitan validarse ante el tribunal de la razón; de la manera en que están puestas las cosas, más bien, se trata de elecciones fundamentales respecto de cuestiones de vida o muerte: si la república no abre los brazos a todos, muere la república. "América... ha salvarse con sus indios" (VI 13).

De este modo, se invierten ciertas jerarquías que dominan el pensamiento político moderno. La organización del Estado no se encuentra fundada en una "ciencia" de la naturaleza humana. Desde luego, Martí no niega que los estadistas se deban al estudio de la naturaleza y señala que toda forma de gobierno debe ajustarse a la constitución propia del país. Pero esto es como afirmar que un escritor debe conocer el idioma en que escribe, lo que no 
significa que del estudio de la gramática salga el argumento de su próxima novela.

No hay fórmulas para trabajar la heterogeneidad, del mismo modo que no hay recetas para la poesía. En todo caso, puede decirse que los poetas no ven contradicciones: buscan una unidad que no está basada en un sistema único, en un discurso absoluto, excluyente y totalizante, sino en un trabajo sobre el lenguaje que restituye la infinita diversidad de lo real. En este punto, el discurso político de Martí es parte de su proyecto estético.

\section{REFERENCIAS}

Descartes, René. 1974. Oeuvres de Descartes. Charles Adam y Paul Tannery (ed). París: Vrin.

Hume, David. 1978. A Treatise of Human Nature. Selby-Bigge (ed). Oxford and New York: Clarendon Press and Oxford University Press.

Kundera, Milan. 1986. L'Art du roman: essai. París: Gallimard.

Locke, John. 1959. An Essay concerning Human Understanding. Alexander Campbell Fraser (ed). New York: Dover Publications.

Lukács, Georg. 1920. Die theorie des romans. Ein geschichtsphilosophischer Versuch uber die Formen der grossen Epik. Berlín: P. Cassirer.

Martí, José. 1963. Obras completas. Habana: Editorial Nacional de Cuba.

Ortega y Gasset, José. 1984. Meditaciones del Quijote. Madrid: Cátedra.

Watt, Ian. 1964. The rise of the novel. Studies in Defoe, Richardson and Fielding. Berkeley: University of California Press. 